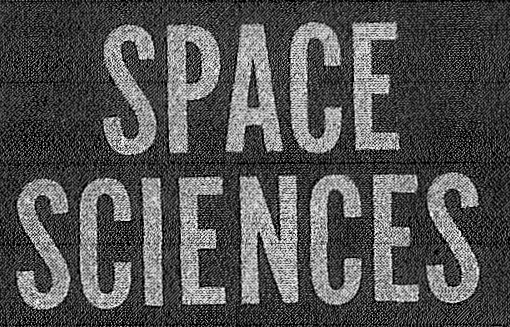

$N 69-31324$

NASA CR-103309

REAL TIME SYSTEMS AND PUBLIC INFORMATION

by

C. West Churchman

Internal Working Paper No. 96

December, 1968

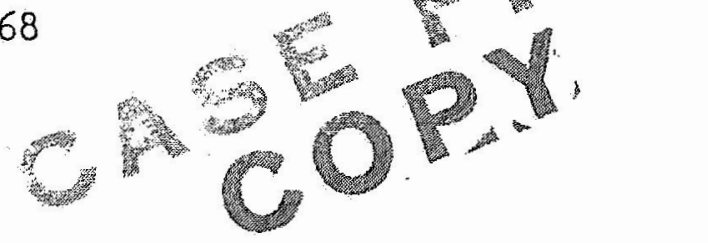

UNIVERSITY OF CALIFORNIA, BERKELEY 
REAL TIME SYSTEMS AND PUBLIC INFORMATION

\author{
by \\ C. West Churchman \\ Internal Working Paper No. 96 \\ December, 1968
}

This research was supported in part by the National Aeronautics and Space Administration under General Grant \#NGL 05-003-012 under the University of California.

\author{
Space Sciences Laboratory \\ Social Sciences Project \\ University of California \\ Berkeley
}




\title{
REAL TIME SYSTEMS AND PUBLIC INFORMATION*
}

\author{
by \\ C. West Churchman \\ University of California, Berkeley
}

It is perhaps obvious that computer technology will open up a new era in public information in the coming decade. What is not so obvious at all is the proper design of the future information systems. Nor do I sense any simple answers.

The questions that come to mind with regard to public information systems are these:

1. Is it feasible to build systems which will more accurately and quickly inform the public on major issues of social policy?

2. If so, is it desirable to build such systems?

3. Is it feasible to build systems which will more accurately report to the legislative and executive branches of government the opinions of the public on social policy?

4. If so, is it desirable to build such systems?

As I say, none of these questions seem to me to have an obvious answer. In the case of the first, it is easy to point out that there exist "manuel" systems, like the New York Times or the radio-TV, which do a reasonably good job of informing the public, but which are not widely used. Are we to expect that merely increasing the facility of access will lead to wider use? But is a more informed public socially desirable? And if legislators could react more quickly to changes in public opinion, would this be desirable?

In order to make the point that these questions have no simple

\footnotetext{
*Presented at the Fall Joint Computer Conference on Real Time Information Systems and the Public Interest, December, 1968.
} 
answer, I'd like to contrast two "world vlews" of the public and its value system, both world views being plausible, but each leading to a different answer to the questions I've posed.

In the first world of the public, the citizen is viewed as a living entity who seeks to attain certain "life goals." In a democratic society, these goals may vary considerably and often will come in conflict. The aim of government is to resolve such conflicts fairly, and to use the national resources to come as near as possible to aiding as many citizens as possible to attain their respective goals. In such a world, information plays a very important role. The citizen needs to know the policies of the government with respect to matters that are relevant to him. If it is the case that the government plans to implement a policy, the citizen should be able to inform his representatives about the consequences of such a policy vis-a-vis his goals. The measure of performance of the information system is the extent to which it removes ignorance, ignorance on the part of both citizen and representative. Consequently, the answer to all four of my questions, according to this world view, is "yes," but the critical point is that the information system needs to be supplemented by a vast educational program. The citizen needs to learn the value of information. He must come to realize that acquiring and transmitting information is an essential part of his value system, so that he will freely seek to be well informed. Hence the government must see to it that the information systems are of the highest quality, and that the public is made aware of their value.

Admittedly, this first world view is a bit simplistic, but when painted in more complicated detail it becomes quite attractive to the social planner. It justifies a social commitment of large resources to the building of better information systems. 
The second world view is also plausible, but by no means as attractive to the system designer. It says that there is no such thing as accurate or objective information, especially in the context of social policy. Instead, so-called "information" is simply one kind of incentive, which can be used by one person or group to influence the behavior of another person or group. It is, in fact, a commodity with its own price, a commodity that serves the purpose of shaping social action. When a person "informs" another, he uses up some of his commodity for the sake of getting the other person to act in ways desirable to him. Thus one man "informs" the citizens of the USA that the North Vietnamese massacred 60,000 Catholics, while another "informs" us that the United States Air Force in its bombings massacred an equivalent number of North Vietnamese civilians. Both are using their information commodity to attain a reaction, either for or against the war. Note that both must be concerned with timing; the commodity is in fact "used up" when information is transmitted. The repeated use of the same information has a quite different effect from the first application.

According to this second world view of public information, the answers to my four questions are generally in the negative. By creating more powerful information systems, we shall be giving certain power groups a tool to maniupulate public action. Which group benefits depends on who designs the system, but the net effect will be one in which political power is enhanced. Inevitably, therefore, a reaction will set in, either civil war or fascism, if only one public information system is designed. What needs to be examined at the outset is the legal and moral aspects of such systems, and this examination will inevitably lead us to conclude that there should at least be competing information systems. In other words, there should be a free market of the commodity. 
This world view is also rather simplistic. In order to enrich it, we might listen some more to the protagonist of the first world view. In his rebuttal, he will point out that of course the designers of the system need to inform the public about the reliability of the information. It is true, he says, that so-called information is often mere subjective opinion. But well documented and objective facts are not the inventions of scheming minds; they are "there" and cannot be changed. A fact is $a$ fact, after all.

To this rebuttal, the other side points out that there are two ways to deceive a person even though what you tell him is the "truth." One way is to tell him only a part of the story, i.e., to select the data. It is not the case that the New York Times prints all the news that's fit to print, because such a task is impossible. Instead it filters out "uninteresting" news, using its own value system to do so. The second way is to interpret the data. No fact is "pure." Whenever I tell you something, I must include shades of meaning and inference, either explicitly or implicitly. This is especially true when the data are supposed to be relevant to policy making. If I tell you that the USSR will produce more engineers in 1970 than the USA, this is not a pure fact, especially if the telling occurs in the environment of alarm about the arms race. The "datum" is attached to a world view, and cannot be detached from it. Hence it is simply impossible to warn the citizen about reliability in any real sense. Furthermore, it is doubtful whether there is any true scale of reliability of information.

The debate is not apt to have any end, because both sides argue in the context of ignorance. Neither one has knowledge of the real social system, though each can tell a plausible story about his view of it. My sympathies are with the second side, because I suspect that the first is 
somewhat dishonest: by trying to insist on objective information, it also tries to escape from moral commitment. Its proponents want us to believe that a fact stands there independent of one's purposes. Hence they believe that the designer of information systems does not have to declare what his opponent takes to be the implicitly assumed moral assumptions. Furthermore, I believe that all too many legislators and executives aid and abet this moral deception.

I wouldn't vote for the second viewpoint if it ended in relativism, i.e., in the position that information can mean whatever one wants it to mean. Rather, I take it to be saying that (I) there is such a thing as morality in social policy making, (2) the morality dictates in part which goals are legitimate and which are not, and (3) that information is valid which directs us towards the moral goals. That is, the design of an information system ought not to be accomplished without an explicit moral commitment. Finally, no one should claim expertise on morality, which is the voice of all people, past, present, and future. Morality is above all a matter of experience, or even of experiment, in which all of us are both subjects and observers.

The unpopular antithesis I've been developing in this paper says in effect that as a culture we are morally immature, and that this immaturity comes to be a serious threat every time anyone proposes a technological innovation. We don't understand the moral basis for building freeways, supersonic transports or public information systems. We are not mature enough to deserve the fruits of technological change. Because we are childish in our morality, we believe we can keep shifting moral responsibility. We say that it's not up to the system scientist to find the moral basis for an information system; this is a matter for managers or the public to decide. No study of morality ever seems to get into the proposals 
or RFP's. We even childishly assert that it's meaningless to try to study moral issues because people have been trying for centuries "without success." Only a child believes that "success" means satisfaction and removal of the problem. Every adult knows that serious problems are never resolved, and must be studied continuously and deeply.

The antithesis is bound to be unpopular and probably will go unheeded. No child likes to be told that he's behaving like a child, especially when physically he is quite strong and mature. 